\title{
CHALLENGES OF PROFESSIONALIZA- TION: BRIDGING RESEARCH AND PRACTICE THROUGH A BODY OF KNOWLEDGE FOR IT SPECIALISTS
}

\author{
Juhani Iivari ${ }^{1}$, Rudy Hirschheim ${ }^{2}$ and H.K. Klein ${ }^{3}$ \\ 1 Department of Information Processing Science, University of Oulu, P.O. Box 3000, FIN- \\ 90014 Oulun yliopisto, FI \\ 2 E. J. Ourso College of Business, Louisiana State University, Baton Rouge, LA 70803, US \\ 3 School of Management, SUNY-Binghamton, Binghamton, NY 13902, US
}

\begin{abstract}
This paper suggests that the interpretation and development of IT occupations as knowledge work might provide a more realistic avenue to proceed towards more professional practice in the IT field rather than the ambition of trying to establish them as true professions. The idea of knowledge work leads us to focus on the body of knowledge possessed by it specialists, which is the hallmark of all professions. The on-going debate about the practical relevance of IT research suggests that there is a significant gap between research and practice in the IT field. The paper discusses how the gap could be bridged by making IT research more sensitive to practice.
\end{abstract}

\section{INTRODUCTION}

A joint project of the ACM and IEEE Computer Society to define Software Engineering (SE) as a profession is perhaps the most serious attempt to professionalize an IT occupation. ${ }^{1}$ The project proposed a guide for the SE body of

${ }^{1}$ There is no standard definition of IT occupations (Kaarst-Brown and Guzman 2004). Without any formal definition IT occupations are exemplified by jobs such as programmer, telecommunication specialist, database specialist, software engineer, human-computer specialist, systems designer, systems analysts, systems support, help desk, (IT) team leader,

Please use the following format when citing this chapter:

Iivari, J., Hirschheim, R. and Klein, H.K., 2008, in IFIP International Federation for Information Processing, Volume 274; Advances in Information Systems Research, Education and Practice; David Avison, George M. Kasper, Barbara Pernici, Isabel Ramos, Dewald Roode; (Boston: Springer), pp. 15-27. 
knowledge (SWEBOK 2004) as well as a code of ethics and professional practices (SWECOE 2000). More recently, IFIP has also started a program to promote professionalization. The IFIP Professional Practice Task Force recommends that IFIP should initiate a vigorous activity to promote professionalism worldwide (IFIP 2007). The Task Force also emphasizes that the voice of the IT practitioner should be clearly and powerfully expressed alongside other competing groups.

Whilst these goals are laudable, IFIP is somewhat silent on how to effect such professionalization, in particular when it is still an open question if the aforementioned $\mathrm{ACM} /$ IEEE project will manage to establish SE as a profession with associated accreditation, certification and licensing practices.

This paper takes a positive position to "professionalization" of IT occupations as far as the enhancement of ethical principles, knowledge and expertise is concerned. However, we are much more circumspect with the enforcement aspects of professionalization, i.e. certification and licensing which would establish SE and IS as true professions. Instead, we propose that IT occupations may be developed in a professional direction by viewing themselves as knowledge work and by strengthening their underlying bodies of knowledge (BoK).

The literature on professionalization (e.g. Abbott 1988) suggests that a scientifically grounded body of knowledge is a necessary, but not sufficient condition for any profession. There should also be demand for that knowledge in practice (Collins 1990). The present paper especially focuses on the question of demand for the knowledge produced by IT research institutions. The gap between research and practice in the IT field (e.g. Osterweil, 1996; Benbasat and Zmud 1999) implies that the demand is not self-evident. So, while we encourage the IT communities to take active steps towards creating such professional bodies of knowledge, we also see it as important that the knowledge will be made more relevant for practice. Therefore our special focus is in how to bridge research and practice when specifying bodies of knowledge for IT specialists.

(IT) project manager, CIO, etc. These are often referred to as 'IT specialists'. We also assume that IT specialists earned at least an undergraduate degree in a relevant subject. 


\section{PROFESSIONS AND PROFESSIONALIZATION}

Professions and professionalization are widely discussed in sociology. Sociologists have been particularly interested in how certain occupational groups have managed to persuade society to grant them a privileged position as a profession. Following Abbott (1988) one can identify three major traditions in the literature on professions, strands which are clearly relevant in the current efforts to professionalize IT. The first tradition refers to the early literature on professions dominated by traits of professions such as a service ideal, professional culture and associations, and what the profession stands for. The second tradition focuses on the professionalization process as a sequence of events such as establishing formal education, licensing, founding a national association, developing a code of ethics and school accreditation (Wilensky 1964). The third tradition centers on power (Larson 1977), looking at how a profession is able to achieve its privileged position and maintain it.

But what is a profession? Although there is no consensus on the necessary traits of professions, a system of characteristics such as a unique BoK, code of ethics, lengthy education, control of the entry to the profession, and high autonomy are often associated with professions. Among these the BoK is central (e.g. Abbott 1988; Macdonald, 1995).

There are a few attempts to analyze IT occupations as possible professions. Ensmenger (2000) shows that professional efforts in the computer fields have a long history, starting already in the 1950's and 1960's. Orlikowski and Baroudi (1989) claim that IS specialists (including operators, programmers, analysts and various technical specialists) cannot be considered professions. Ford and Gibbs (1996) conclude that SE as an occupation does not fulfill the traits of a profession.

It is clear that the SE professionalization project has insufficiently discussed the project from the power perspective. It is widely accepted that professionalization efforts have an ideological and political aspect of increasing the status of the occupation in question. Abbott (1988) interprets professionalization as competition between different occupational groups for jurisdiction. Professional 
autonomy, emphasized by Freidson (1988), includes the right to serve as the best experts on affairs related the BoK and to decide about it, to control the education and accreditation of new entrants, and autonomy over the practical aspects of their work (Freidson 1994). Accordingly, professionalization means building 'exclusionary shelters in the market' and providing a market monopoly (Freidsonn 1988; Collins 1990; Macdonald 1995).

Professionalization as standardization of skills provides companies with one coordination mechanism (Minzberg 1983). The rise of outsourcing and especially offshore software development may also play an important role in professionalization, although at this point it is not clear whether it would be pro or con (cf. Sahay et al. 2003). Yet, it is questionable if companies employing IT experts are ready to support professionalization, since the exclusionary shelters may influence the labor market in a way that is not beneficial to employing companies.

In this paper, however, we do not wish to discuss the political side of professionalization of the IT occupations nor do we wish to become strong advocates for professionalization. Instead we focus on analyzing IS as knowledge work, suggesting that this is a more realistic avenue to enhance the expertise of IT specialists and thereby their "professionalism". The advantage of a knowledge work perspective is that it focuses attention on the BoK of IT specialists and the gaps between research and practice without getting involved in the political battle of professionalization, which is considered to lie beyond the scope of this paper.

\section{IT OCCUPATIONS AS KNOWLEDGE WORK}

One possibility for avoiding the political battle of professionalization is to have a more modest goal: to have the IT occupations recognized as knowledge work. This would have the effect of directing attention to the bodies of knowledge of IT specialists. As discussed above a scientifically grounded BoK is a necessary, but not sufficient condition for any profession. 


\subsection{Knowledge work}

Knowledge work $(\mathrm{KW})$ is difficult to define precisely because all work requires knowledge to some extent (Beyerlein et al. 1995, Pyöriä 2005) and because the concept of knowledge is ambiguous (Schultze 2000). Despite the difficulty to define KW there are a number of attempts (see Kelloway and Barling 2000). We propose four criteria to characterize KW (Iivari and Linger 1999):

(i) $\mathrm{KW}$ is based on a demonstrable body of knowledge (BoK),

(ii) entails working on representations (data) of the objects of work,

(iii) stipulates a deep, theoretical understanding of the objects of work, and

(iv) KW produces results, which entail knowledge as their essential ingredient.

The first characteristic emphasizes the significance of a BoK, often codified, as a resource in KW. This is consistent with Stehr's (1992) emphasis of the relational structures of knowledge-based occupations, i.e. their relation to socially constructed forms and stocks of knowledge. This underscores that knowledge workers "are not isolated individuals but derive and defend their expertise by virtue of their memberships and standing in communities of" knowledge workers.

The second characteristic emphasizes the abstract and detached nature of KW. Working indirectly through the representation of the object of work requires intellective skills (Zuboff 1988), in contrast to action-centered skills.

The third characteristic, a deep, theoretical understanding of the object of work, means that knowledge work typically requires several years' training, usually through formal high-level education. This theoretical understanding may help the knowledge worker to deal with new and exceptional cases, but in particular to adapt to changes in the objects of work, to accommodate changes in the BoK, and to adopt technologies allowing new representations of the object of work.

The fourth characteristic does not stipulate that the output of KW is perceived primarily as knowledge but that the output includes knowledge as an essential ingredient. Overall, our conception of $\mathrm{KW}$ views it primarily as knowledge applying work rather than as creative, knowledge producing work (Machlup 1962; Schultze 2000). Note, however, that much of the creative knowledge producing work is also knowledge applying work, and that our interpretation does not deny 
that knowledge workers and even their employer organizations are learning through their work. In that sense, $\mathrm{KW}$ is producing knowledge, but it is not necessarily the primary purpose of the work.

Referring to the topic of the present paper, it is apparent that software and information systems development satisfies characteristics (ii) and (iv) above. The question is whether IS development is based on a systematic BoK and whether the development requires any deep, theoretical understanding of software/information systems as the objects of that work.

\subsection{Bodies of Knowledge for IT specialists}

A body of knowledge is knowledge of the relevant phenomena associated with KW as an activity. To our knowledge, the Software Engineering Body of Knowledge (SWEBOK) is the most ambitious attempt to define a BoK for one IT occupation. SWEBOK (2004) identifies ten knowledge areas: software requirements, software design, software construction, software testing, software maintenance, software configuration management, software engineering management, software engineering process, software engineering tools and methods, software quality.

To broaden our vision of the required potential scope of the BoK to be considered as relevant for IT specialists, we note the following recent computer curricula which have specified bodies of knowledge for five 'computing disciplines': Computer Engineering, Computer Science, Software Engineering, Information Systems, and Information Technology (Computing Curricula 2005).

Iivari et al. (2004) suggests five broad knowledge areas for IS specialists: technology knowledge, application domain knowledge, organizational knowledge, IS application knowledge, and systems development process knowledge. Technology knowledge refers to knowledge associated with understanding the types of hardware and software available and how and where they might be applied. Application domain knowledge refers to knowledge about the application domain for which an IS is built. For example, in the case of accounting information systems, the application domain knowledge relates to accounting concepts and principles. Organizational knowledge is knowledge "about the social and economic processes 
in the organizational contexts in which the IS is to be developed and used" (Jones and Walsham, 1992). IS application knowledge is the knowledge about typical IS applications, their structure, functionality, behavior and use, in a given application domain. It includes the knowledge of possibilities to support activities in the intraand inter-organizational context by IS applications in a specific application domain. Systems development process knowledge refers to the tools, techniques, methods, approaches and principles used in systems development.

Iivari et al. (2004) go on to describe how these five knowledge areas form a nascent BoK for IS development. In this paper, we now wish to take these five knowledge areas and see how they differ from the perspective of research and practice. In particular, we see knowledge generated through research to be more general in nature, while the knowledge used in practice is more contextual. It is apparent that there exists gaps between the general and contextual knowledge; and it is in these gaps that a more professional BoK could be of help.

\section{THE RELATIONSHIP BETWEEN RESEARCH AND PRACTICE}

The on-going debate about the practical relevance of IS research (see Schauer 2007 for a review) suggests that there is a significant gap between research and practice in the IS field. The SE community has also suffered a similar dilemma (e.g. Osterweil 1996).

Often the assumption in the debate is that academic knowledge does not sufficiently influence practice. This section reverses the view and looks at how practice could better influence research, contending that we in academia should pay more attention and give more respect to the experience-based knowledge of practitioners when attempting to specify a BoK for IT specialists. Indeed, Klein and Hirschheim (2008) offer a number of change strategies for academia to better take into account the knowledge possessed by practitioners. Yet, if one considers the continued problems and failures of information systems and software development, it is obvious that we cannot accept the current practice and its underlying 
knowledge uncritically. To this end, we offer a framework for thinking about a BoK which embraces the knowledge generated from both research ('general' or 'theoretical' knowledge) and practice ('contextual' or 'experiential' knowledge).

\subsection{Academic and practical knowledge}

One of the reasons for the chasm between academia and practice is the different nature of knowledge on which they focus. Classical Greek epistemology illustrates the difference by distinguishing episteme, techne, phronesis, and metis (Baumard 1999). Episteme is abstract and general theoretical knowledge, while techne describes the practical knowledge in craft and art covering techniques and artifacts which provide methods and means to accomplish tasks.

The practice of developing and applying IT normally takes place in an organizational or inter-organizational context. Phronesis refers to social knowledge required in our everyday interaction with other people. Hirschheim and Klein (2003) characterize phronesis (or applicative knowledge as they call it) as closely related to a person's identity, emotions and interests, and rooted in one's lived experience and especially the tradition into which someone is born and into which he/she has chosen to integrate. They also point out how critical applicative knowledge is for achieving mutual understanding and consensus when developing information systems.

The practice of developing and applying IT also takes place in a dynamic context. Every situation is potentially new and unique. To address these new and unique situations successfully one needs knowledge that ancient Greeks called metis. Baumard (1999) translates it into "conjectural knowledge" and Spender (1996) characterizes it as cunning and shrewdness. Metis can be interpreted to include improvisation as situated performance where thinking and action emerge simultaneously at the spur of the moment (Ciborra 1999).

While theoretical knowledge (episteme) is considered the most valuable knowledge produced by research, practitioners presumably are more interested in techne, i.e. effective means to achieve their goals, than episteme as abstract theories do not inform them about effective action. Yet, to apply technology suc- 
cessfully, practitioners need phronesis and metis. One should note, however, that phronesis and metis are highly situated and therefore difficult to separate from the concrete context in which they are rooted and where they emerged.

\subsection{How to bridge the gap between research and practice?}

We believe the challenge for the IT field is to develop a BoK which embraces both research-originated and practice-originated IT knowledge and bridges the gaps between the two. Referring to the contextuality of practice-originated knowledge (phronesis and metis) we do not see any short-term solutions to bridge the two, as it requires profound changes on both sides that can only be addressed with a long time perspective.

Schauer (2007) analyzes the relevance vs. rigor debate in IS and distills a number of recommendations from that literature. Table 1 is a partial summary of the recommendations from her work, but extends them in many ways. We note that many of the recommendations in Table 1 are not particularly novel, and that different communities as well as different regional areas and countries differ in the degree and extent to which they already follow the recommendations. The point of Table 1 is that one should be as comprehensive and systematic in the measures to bridge research and practice as possible.

\section{CONCLUSIONS}

Several authors have recommended that IT should emulate established professions to bridge the gap between research and practice ( $c f$. Davenport and Markus 1999). While we agree that the analogy between IT and more established professions such as engineering or medicine and law is informative, one must also be conscious of essential differences between these professions and the IT field. One must keep in mind that, although medicine has become ever more dependent on technology it is ultimately concerned with the human body which has remained essentially the same for hundreds of thousands of years. The IT field on the con- 
trary deals with a constantly evolving artificial world of IT artifacts, which are developed and applied in the artificial worlds of organizations and societies. Law is also concerned with a socially constructed artificial world, but the law profession is lucky in the sense that it actively constructs the artificial world called "law", i.e. the system of legal procedures, codes and precedents (Collins 1990). In the IT field, the IT experts cannot control which IT artifacts are developed and how they are applied. In fact, the IT field probably resembles engineering more than anything else. If so, it is worthwhile realizing that engineering has been much less successful in its professionalization than medicine and law (Collins 1990).

The case of engineers illustrates that the existence of a BoK and the demand for that knowledge in practice is not enough for professionalization. It requires the capability to monopolize that knowledge. The gap between research and practice in the IT field led us to wonder if there is real demand for the knowledge that the discipline provides. Therefore, in our view it is not sufficient that we specify a BoK for the IT disciplines but that knowledge should also have practical relevance. In this paper, we have specifically focused on the issue of how to bridge the gap between research and practice by making research more sensitive to practice. In conclusion, while the professionalization model might inform us on how to bridge the gap between research and practice in the IT field, the very same gap also hinders all professionalization efforts in our field.

Although we support stronger sensitivity to practice, one should not interpret this to imply that the current practice should have the right to decide research directions. From the standpoint of practice and society, research needs to have autonomy for at least two reasons. One is to play its intellectual role of fundamental criticism as defined by Etzioni (1968) and discussed in more detail in Klein and Myers (2007). The other is that research as an institution needs to develop its ideas freely so that it can be a productive contributor to the global marketplace of ideas. Yet, we believe that researchers should also always seriously assess if their research projects have any chance of producing knowledge that could affect practice. Therefore, it is extremely important that we do not bring in rigidities that jeo- 
pardize the freedom of research and its potential innovativeness when attempting to develop the IT field towards more professionalization.

Table 1: Recommendations for how to bridge research and practice

\begin{tabular}{|c|c|}
\hline Category & Recommendations \\
\hline \multirow[t]{4}{*}{$\begin{array}{l}\text { Improve condi- } \\
\text { tions for relevant } \\
\text { IT research }\end{array}$} & $\begin{array}{l}\text { Promote mobility between academia and industry } \\
\text { - recruit more faculty with industry experience in universities } \\
\text { - provide university faculty with opportunities to have sabbati- } \\
\text { cals at business organizations } \\
\text { - have more IT PhDs working in industry }\end{array}$ \\
\hline & $\begin{array}{l}\text { Change doctoral education to address better industry interests } \\
\text { - recruit doctoral students from industry } \\
\text { - create special doctoral programs for practitioners interested in } \\
\text { doctoral studies } \\
\text { - provide funding for doctoral students from industry }\end{array}$ \\
\hline & $\begin{array}{l}\text { Foster joint university and industry research projects } \\
\text { - provide special funding for joint projects } \\
\text { - simplify the bureaucracy with funding }\end{array}$ \\
\hline & Encourage responsible consulting by faculty members \\
\hline \multirow[t]{3}{*}{$\begin{array}{l}\text { Conduct more } \\
\text { relevant IT re- } \\
\text { search }\end{array}$} & $\begin{array}{l}\text { Strive for relevant research questions and results } \\
\text { - joint university and industry research projects } \\
\text { - make sure that the joint projects also have high scientific am- } \\
\text { bitions } \\
\text { - integrate joint projects with a research program that has a } \\
\text { longer time frame } \\
\text { - focus on applied theory research, evaluation research, policy } \\
\text { research and design science research }\end{array}$ \\
\hline & $\begin{array}{l}\text { Apply research methods that support industry participation and } \\
\text { enable the capitalization of practical experience of researchers } \\
\text { - emphasis on qualitative research methods } \\
\text { - action research and constructive (design science) research }\end{array}$ \\
\hline & $\begin{array}{l}\text { Produce better consumable research articles } \\
\text { - publish in both academic publication forums and practitioner- } \\
\text { oriented outlets } \\
\text { - write in a way that is more targeted to practitioners } \\
\text { - organize the results in a way that is action-oriented }\end{array}$ \\
\hline $\begin{array}{l}\text { Increase the aca- } \\
\text { demic acceptance } \\
\text { of relevant re- } \\
\text { search }\end{array}$ & $\begin{array}{l}\text { Reward publications in practitioner outlets } \\
\text { Establish new publication outlets } \\
\text { Change academic journal policies } \\
\text { Broaden acceptable dissertation research }\end{array}$ \\
\hline
\end{tabular}




\section{REFERENCES}

Abbott, A., The System of Professions: An Essay on the Division of Expert Labor, The University of Chicago Press, Chicago, 1988

Benbasat, I. and Zmud, R., Empirical Research in Information Systems: The Practice of Relevance, MIS Quarterly, 23(1), 1999, pp. 3-16.

Beyerlein, M.M., Johnson, D.A. and Beyerlein, S.T. (eds.), Knowledge Work in Teams, JAI Press, Greenwich, CT, 1995

Ciborra, C., Notes on improvisation and time in organizations, Accounting, Management and Information Technology, 9, 1999, pp. 77-94

Collins, R., Changing conceptions in the sociology of the professions, in Tortsnedahl, R. and Burrage, M., The Formation of Professions: Knowledge, State and Strategy, SAGE Publications, London, 1990, pp. 11-23

Computing Curricula 2005, The Overview Report Covering Undergraduate Degree Programs in Computing for Computer Engineering, Computer Science, Information Systems, Information Technology and Software Engineering. The Joint Task Force for Computing Curricula, 2005

Davenport, T. and Markus, M. L., Rigor vs. Relevance Revisited: Response to Benbasat and Zmud, MIS Quarterly, 23(1), 1999, pp. 19-23.

Etzioni, A., The Active Society, Collier-McMillan, The Free Press, 1968.

Ensmenger, N.L. The question of professionalism' in the computer fields, IEEE Annals of the History of Computing, October-December 2001, pp. 56-74

Ford, G. and Gibbs, N.E., A mature profession of software engineering, Technical Report CMU/SEI-96-TR-004, Software Engineering Institute, Carnegie Mellon University, Pittsburgh, 1996

Freidson, E., Professions of Medicine: A Study of the Sociology of Applied Knowledge, The University of Chicago Press, 1988 (First published 1970)

Freidson, E., Professionalism Reborn, Polity Press, 1994

Hirschheim, R. and Klein, H. K., Crisis in the IS Field? A Critical Reflection on the State of the Discipline, Journal of the Association for Information Systems, 4(5), 2003, pp.237-293

IFIP, First Report of the IFIP Professional Practice Task Force, January 2007

Iivari, J., Hirschheim, R. and Klein, H.K., Towards a distinctive body of knowledge for information systems experts: coding ISD process knowledge in two IS journals, Information Systems Journal, 14(4), 2004, pp. 313-342

Iivari, J. and Linger, H., Knowledge Work as Collaborative Work: A Situated Activity Theory View, Proceedings of the 32nd Hawaii International Conference on System Sciences, 1999

Jones, M. and Walsham, G., The limits of the knowledge: Organizational and design knowledge in systems development, in Kendall, K.E. (ed.), The Impact of Computer Supported Technologies on Information Systems Development, Elsevier Science Publishers B.V (North-Holland), Amsterdam, 1992, pp. 195-213 
Kaarst-Brown, M.L. and Guzman, I.R., Who is the 'IT workforce'? Challenges facing policymakers, educators, management, and research, Proceedings of the 2005 ACM SIGMIS CPR Conference, Atlanta, 2005, pp. 1-8

Kelloway, E.K. and Barling, J., Knowledge work as organizational behavior, International Journal of Management Reviews, Vol. 2, No. 3, 2000, pp. 287-304

Klein, H. K. and Hirschheim, R., The Structure of the IS Discipline Reconsidered: Implications and Reflections from a Community of Practice Perspective, Information and Organization, forthcoming

Klein, H. K. and Myers, M., A set of principles for conducting and evaluating critical field studies in information systems, submitted, Nov. 2007.

Macdonald, K.M., The Sociology of the Professions, Sage Publications, London, 1995

Machlup, F., The Production and Distribution of Knowledge in the United States, Princeton University Press, Princeton, NJ, 1962

Maclaughlin, J. and Webster, A., Rationalizing knowledge: IT systems, professional identities and power, Sociological Review, 46(4), 1998, pp. 781-802

Minzberg, H., Structure in Fives: Designing Effective Organizations, Prentice Hall, Englewood Cliffs, NJ, 1983

Orlikowski, W. and Baroudi, J., The information systems profession: Myth or reality, Office: Technology and People, 4(1), 1989, pp. 13-30

Osterweil, L., Strategic Directions in Software Quality, ACM Computing Surveys, 28(4), 1996, pp. 738-750

Pyöriä, P., The concept of knowledge work revisited, Journal of Knowledge Management, 9(3), 2005, pp. 116-127

Sahay, S. Nicholson, B. and Krishna S., Global Software Work: Micro-Studies Across Borders, Cambridge University Press, 2003

Schauer, C., Relevance and Success of IS Teaching and Research, An Analysis of the "Relevance Debate”, ICB-Research Report No. 19, Universität DuisburgEssen, Essen, Germany, 2007

Schultze, U., A confessional account of an ethnography about knowledge work, MIS Quarterly, 24(1), 2000, pp. 1-41

Spender, J.-C., Making knowledge the basis of a dynamic theory of the firm, Strategic Management Journal, 17, 1996, pp. 45-62

Stehr, N., Experts, counselors and advisers, in Stehr, N. and Ericsson, R.V. (eds.), The Culture and Power of Knowledge, Walter de Gruyter, Berlin, 1992, pp. 107-155

SWEBOK, Guide to the Software Engineering Body of Knowledge, 2004 Version, February IEEE, 2004 (www.swebok.org)

SWECOE, Software Engineering Code of Ethics and Professional Practice, (www.cs.etsu.edu/seeri/secode.htm)

Wilensky, H.C., The professionalization for everyone, American Journal of Sociology, 7, 1964, pp. 137-158

Zuboff, S., In the Age of the Smart Machine, The Future of Work and Power, Heineman, Oxford, 1988 